9-9-20 there was no staining anywhere. 10-27-20 right and left both stain slightly. $12-28-20$ right eye seemed quiet. Left slightly progressive. 2-10-21 right eye very slightly active. Left eye cornea all gone except slight hazy center. Left eye progressed steadily until the center was destroyed. All the cornea was involved. Very slight progress in right. Right eye about same as at present for last two months. There may be very slight activity at upper inner portion of right limbus.

Previous cases of Mooren's ulcer in wur experience were cured by deep cauterization with nitric acid. In this case, the following measures were employed. The actual cautery, excision of the conjunctiva around the ulcer, thermophore, iodin, delimiting keratotomy were used in the right eye without avail until the vision was very much reduced. In the left eye, the advance seemed to be stopped under present treatment of applications of weak silver nitrat to the lids, and diluted tricholoracetic acid to the active portions of the ulcer. Radium was tried but not the $X$-ray.

\section{Rupture of the Choroid.}

Dr. I.. G. Howard stated: C. C. C. came in July, 1921, complaining of loss of vision in right eye. The vision in the right eye had been somewhat impaired, following a traumatism from a sling shot at the age of fourteen years, but was still serviceable, up until twc weeks ago. Two weeks ago, patient was struck in right eye by some unknown object which, however, did not bruise, cut or contuse the lid or eyeball externally. He then experienced sudden and almost complete loss of vision in that eye. He could still see objects but very indistinctly. Condition has not improved since then. Has occasional mild pain in eye but not severe. Sees better at night. Strong light dazzles the right cye. Family and past medical history negative. Admits ordinary diseases of childhood. Denies venereal disease. July, 1921. Pupil $6 \mathrm{~mm}$. Does not react. Cornea clear. Lenticular opacity. Fundus not seen distinctly because of vitreous haziness. O. D. V. cannot count fingers. No central vision.

December, 1921. O. D. V. counts fingers at three meters. O. S. V. 20/20. Pupil fixed, $6 \mathrm{~mm}$. Tension normal. Opacity in lens. Vitreous clear. Choroidal tear thru macula.

Discussion.-Dr. Dean saw the case when it first came in. It was never decided just what caused the injury in this case. $\mathrm{He}$ thinks it was possibly a bird flying against the eye. The sudden onset of blindness was probably due to haze in the vitreous. There was no evidence of intraocular hemorrhage.

DR. S. R. GIFFord.

Secretary.

\section{ST. LOUIS OPHTHALMIC SOCIETY.}

March 24th, 1922.

Dr. F. E. Woodruff, Presiding.

Eyes of Military Recruits.

Dr. J. A. Flury read a paper on the Eye Findings in 45.000 Men Entering Military Service at Camp I.ee, which is not available for publication.

\section{Neuropathic Keratitis with Special Re- lationship to Sinuses.}

Dr. J. W. Charles dwelt upon the theory that dendritic keratitis is a terminal nerve lesion and reported a case which seemed to be caused by ethmoidal disease. This is published in full. See p. 703.

Discussion.-Dr. IV. A. Shoemaker said: The case to which Dr. Charles has referred is that of a man aged about 40 , who consulted me Jan., 1921, with the following history: For the last :hree days both eyes had been inflamed. He has a good deal of secretion in the mornings and more or less during the day. Examination revealed a severe staphylococcus conjunctivitis. For use at home I gave him a solution of zinc sulphat.

Jan. 30th the left eye began to water, pain and feel rough. Examination revealed a small spot of superficial keratitis, which stained with fluorescein. Feb. 1st, there was an extension downward of the process; the cornea 
was anesthetic, and I realized that I had a neuropathic keratitis to deal with, and proceeded to look for the cause. Teeth and tonsils were found to be normal. Blood tests negative, with the exception of hemoglobin, which was 65 . Metabolism 99.1.

Patient had had, for years, a tuberculous left kidney, with a sinus that discharged more or less; but otherwise seemed in good health. The corneal inflammation was not looked upon as tubercular.

The rhinologist reported a bilateral suppurative ethmo-sphenoiditis, for which he had been giving him conservative treatment for some months. As the eye was not improving under treatment, I advised a radical operation on both ethmoids and sphenoids. Two days after the operation the eyes began to improve, and by Feb. 15th, were practically well.

\section{Adler's Pencil for Detection of Color Blindness.}

Dr. J. W. Chiarles showed how a patient was discovered in such inconsistent answers, in matching ninetyeight shades of colors in the Adler test, that either malingering or hysteria was certain ; also the easily recorded and demonstrable results of the test.

\section{Case of Hypothyroidism.}

Dr. J. W. Charles reported the case of a woman, 53 years old, who consulted him in 1918 , with a vitreous hemorrhage in one eye and papilledema with a marked strapping of vessels in the other. She was about five feet tall, and weighed 270 pounds. Her blood pressure was $260 / 140$; there was great dyspnea on slight exertion; the heart was greatly enlarged with myocarditis; the pulse was 90 ; the urine contained $1 / 10 \%$ albumin and many hyalin and granular casts. She was put to bed and given thyroid. Upon her second visit in the fall of 1921, the patient weighed only 170 pounds, her heart and kidneys seemed normal. She is now doing all of her house work and taking care of a husband with heart disease. The appearance of the fundus of her good eye is very much better in every respect, the vision being 23/19.

The sequence in this case was undoubtedly hypothyroidism, obesity, strain on heart and bloodvessels, high blood pressure with its consequences (eye signs, and temporary damage to the kidneys), with complete relief by means of rest and thyroid feeding.

J. W. Charles,

Editor.

\section{WASHINGTON INTERNATIONAL CONGRESS.}

\section{(Continucd from p. 674)}

Wednesday, April 27th, 1922.

\section{Endophthalmitis Phacoanaphylactica.}

Dr. F. H. VerhoEFF, and DR. A. N. Lemoine, Boston, Mass. Uhlenhuth in 1903 showed that rabbits could be immunized by repeated intravenous injections of ox lens protein, so that the blood would give the precipitin reacion with lens protein from other animals, but that these immunized animals failed to give the reaction with ox serum. In other words, reaction was tissue specific and not species specific. In 1909 Uhlenhuth and Haendel showed that guinea pigs could even be sensitized to their own lens protein. These results have since been verified by other observers.
It is well known that after injuries to the lens, in some cases inflammatory reaction follows, while in others no such reaction takes place. Some have maintained this inflammatory reaction was always due to infection, others have regarded it as the result of irritation due to lens matter. The latter view was apparently first brought forward by Lagrange and Lacoste, in 1911, who reported eight cases in a series of one hundred cataract extractions. Schirmer had observed cases presenting the same clinical picture, in which he had found the aqueous sterile, but which he did not explain on the basis of irritation from lens matter.

More recently the view that lens matter may cause intraocular inflam- 